\title{
C1 inhibitor deficiency and angioedema of the small intestine masquerading as Crohn's disease
}

\author{
Kelly W Burak MD FRCPC, Gary R May MD FRCPC
}

KW Burak, GR May. C1 inhibitor deficiency and angioedema of the small intestine masquerading as Crohn's disease. Can J Gastroenterol 2000;14(4):349-351. A case of C1 inhibitor deficiency presenting as localized edema of the small intestine is described. A 16-year-old, previously healthy woman presented with recurrent attacks of abdominal pain and vomiting following minor abdominal trauma. Investigations including computed tomography scan and barium studies confirmed localized edema of the jejunum. At laparoscopy, Crohn's disease was suspected; however, a subsequent enteroscopy was normal. Complement levels revealed a low $\mathrm{C} 4$ level, and $\mathrm{C} 1$ inhibitor deficiency was later confirmed. Attacks of abdominal pain began after starting oral contraceptives and have not returned since stopping the birth control pill. This rare cause of abdominal pain is examined, and $\mathrm{C} 1$ inhibitor deficiency and angioedema are reviewed.

Key Words: Angioedema; C1 inhibitor; Oral contraceptives; Small intestinal obstruction

\section{Déficit en inhibiteur de $\mathrm{C} 1$ et angio-oedème} du petit intestin simulant la maladie de Crohn

RÉSUMÉ : Voici un cas de déficit en inhibiteur de C1 qui se manifeste sous la forme d'œdème localisé du petit intestin. Une jeune femme de 16 ans, auparavant en bonne santé, présente des crises répétitives de douleurs abdominales et des vomissements à la suite d'un traumatisme abdominal mineur. Les examens, dont une tomodensitométrie et des explorations au baryum, confirment la présence d'œdème localisé dans le jéjunum. La laparoscopie laisse croire à la maladie de Crohn; toutefois, une entéroscopie ultérieure s'avère normale. Des examens complémentaires révèlent une faible concentration de $\mathrm{C} 4$, et le déficit en inhibiteur de $\mathrm{C} 1$ est confirmé plus tard. Les crises de douleurs abdominales ont commencé après le début de la prise de contraceptifs oraux et sont disparues depuis l'interruption du médicament. L'article analyse ce cas rare de douleurs abdominales et passe en revue le déficit en inhibiteur de C1 et l'angio-oedème.
$\mathrm{C}$ 1 inhibitor (C1-INH) deficiency is a rare disorder that presents with angioedema and may be hereditary or acquired. Gastrointestinal involvement may lead to diarrhea and abdominal pain from bowel obstruction. Recurrent attacks of bowel angioedema are self limiting, but patients who are misdiagnosed may undergo unnecessary surgery or develop narcotic addiction. Although C1-INH deficiency is a rare cause of acute and recurrent abdominal pain, it is important to recognize this condition. The pathophysiology and management of angioedema are reviewed.

\section{CASE PRESENTATION}

A 16-year-old woman presented in May 1998 with severe epigastric abdominal pain, nausea and vomiting. The attack followed minor trauma to the abdomen during a fight at school. There was no hematemesis or melena. She was previously healthy and had no prior gastrointestinal symptoms. She was taking no medications other than an oral contraceptive that had recently been started. She was a nonsmoker and did not drink alcohol. On examination, she was afebrile and hemodynamically stable. She had mild epigastric ten-

This article was a winning entry in the "Consults in Gastroenterology" Case Study Competition, which was initiated and funded with generous sponsorship of Astra Canada, and it is endorsed by the Canadian Association of Gastroenterology. This generous support indicates Astra Canada's commitment to very worthwhile educational initiatives in gastroenterology.

Department of Medicine, University of Calgary, Calgary, Alberta

Correspondence: Dr Kelly Burak, Foothills Hospital, 1403 29th Street Northwest, Calgary, Alberta T2N 2T9. Telephone 403-670-1110, fax 403-270-0995,e-mail burakk@cadvision.com

Accepted for publication July 18, 1999 


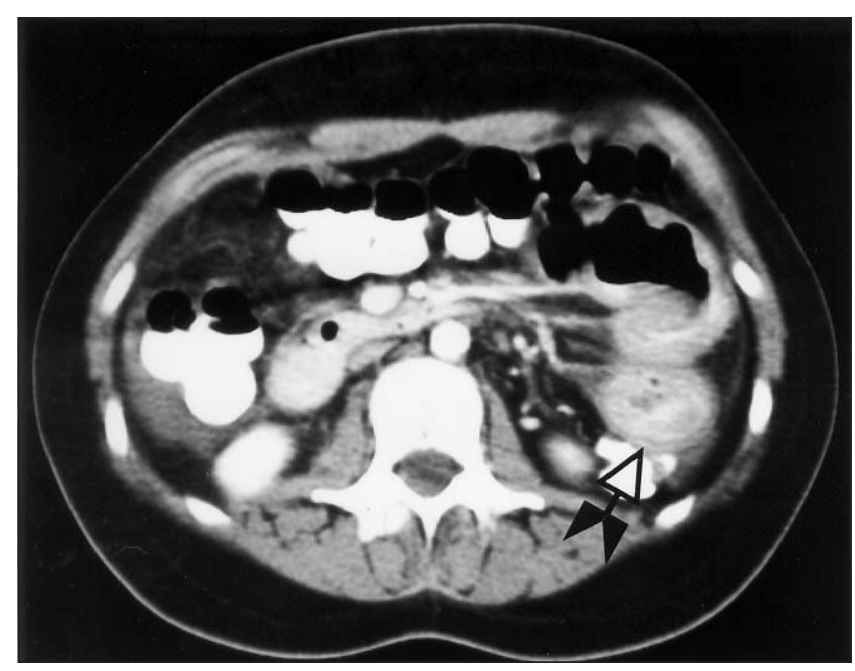

Figure 1) Computed tomography scan during second admission for abdominal pain demonstrating mural thickening in the proximal jejunum (arrow)

derness but no mass or peritoneal signs. Laboratory tests revealed a hemoglobin level of $115 \mathrm{~g} / \mathrm{L}$, and normal electrolyte, amylase and white blood cell levels. An upper gastrointestinal series demonstrated thickening of mucosal folds in the distal duodenum and proximal jejunum, thought to represent an intramural hematoma. There was free fluid in the abdomen and pelvis on abdominal ultrasound. Her pain resolved over $48 \mathrm{~h}$ with intravenous fluids and narcotics.

She returned to the hospital one month later with recurrent epigastric pain and vomiting. Computed tomography (CT) scan revealed free fluid and prominent thickening of the proximal jejunum (Figure 1). An upper gastrointestinal series confirmed small bowel edema extending from the distal duodenum to $10 \mathrm{~cm}$ beyond the ligament of Trietz (Figure 2). The initial diagnosis of mural hemorrhage was questioned because a hematoma should have resolved over the preceding month. Laparoscopy revealed transmural thickening in the first $10 \mathrm{~cm}$ of the jejunum. There was thought to be mild creeping fat in the mesentery. The remainder of the small intestine, including the terminal ileum, was normal. A presumptive diagnosis of Crohn's disease was made, but her symptoms had completely resolved in hospital and she was followed without specific therapy. There was no history of diarrhea, fever or weight loss. She had no extraintestinal manifestations of inflammatory bowel disease, and her family history was unremarkable. Three weeks later, while asymptomatic, a repeat upper gastrointestinal series and small bowel follow-through revealed no abnormalities. Two months later, she was readmitted to hospital with another attack of colicky epigastric pain. On repeat CT scan, jejunal thickening was once again seen, but there was no peritoneal fluid. She was then referred to the authors' institution for enteroscopy. The mucosa of the proximal jejunum appeared normal. Jejunal biopsies were normal. The diagnosis of recurrent small bowel angioedema was considered. Complement levels revealed a normal C3 and low C4 level at less

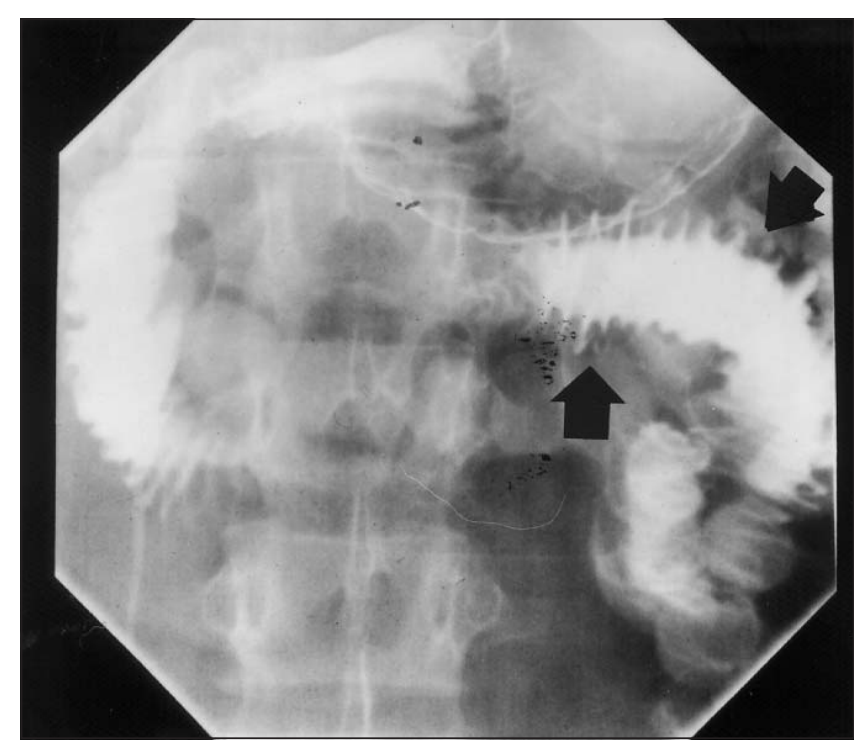

Figure 2) Upper gastrointestinal series demonstrating mucosal edema in the proximal $10 \mathrm{~cm}$ of the jejunum (arrows)

than $0.1 \mathrm{~g} / \mathrm{L}$ (normal 0.13 to $0.45 \mathrm{~g} / \mathrm{L}$ ). The diagnosis of C1INH deficiency was confirmed with a low C1-INH level at less than $0.05 \mathrm{~g} / \mathrm{L}$ (normal 0.15 to $0.35 \mathrm{~g} / \mathrm{L}$ ). She had no history of edema of the face, upper airway or extremities. There was no history of allergy, urticaria or food intolerance. She had no features of autoimmune disease or systemic lupus erythematosus. Her family was screened for C1-INH deficiency. One brother had a borderline C4 level at $0.15 \mathrm{~g} / \mathrm{L}$, but her parents had normal levels. Because the attacks began after she started an oral contraceptive, this medication was discontinued. She has subsequently been well and free of attacks.

\section{DISCUSSION}

Hereditary angioedema (HAE) was first described by Sir William Osler in 1888 (1). HAE is an autosomal dominant disorder with an estimated prevalence of one in 150,000 (2). Defects of the codominantly expressed C1 esterase inhibitor gene located on chromosome 11 are responsible for this disorder (2). A qualitative deficiency in C1-INH (type I HAE) accounts for $85 \%$ of cases. The other $15 \%$ of cases have normal C1-INH levels, but the esterase is nonfunctional (type II HAE) (3). C1 esterase acts as a competitive inhibitor of activated $\mathrm{C} 1 \mathrm{r}$ and $\mathrm{C} 1 \mathrm{~s}$ in the initial steps of the classic complement pathway (Figure 3) (2). It also has inhibitory roles in the intrinsic coagulation pathway and in the formation of bradykinin (2).

HAE is diagnosed based on clinical presentation, measurement of complement levels and a positive family history. Low levels of $\mathrm{C} 4$ are found during and usually between attacks as well. If screening $\mathrm{C} 4$ levels are low, confirmation is made by measuring C1-INH levels directly. Patients have normal C3 levels, and C2 levels are low during attacks but are usually normal between episodes. Patients present with recurrent bouts of nonpitting edema (angioedema) without pruritus or urticaria. HAE affects all races and both sexes equally. It often first appears in childhood and tends to 
worsen during adolescence (4). Almost all patients experience angioedema of the extremities at some time. Twothirds of patients have orofacial or laryngeal swelling, which is a life-threatening condition (2). Rarely, patients develop pleuritic pain, urinary retention or focal neurological symptoms from localized brain edema (4). Involvement of the gastrointestinal tract is common, and patients typically present with diarrhea or symptoms of bowel obstruction. Fluid shifts into the bowel wall or abdominal cavity may be significant enough to cause hypotension. Acute attacks, often associated with fever and leukocytosis, can mimic an acute abdomen and result in laparotomy. If recurrent attacks go undiagnosed, patients may develop narcotic addiction and be labelled drug seekers.

The onset of angioedema is usually gradual over a few hours and tends to resolve over several days. The most frequent trigger of attacks is minor trauma (4). The best example of this is facial and laryngeal edema precipitated by dental extractions or tonsillectomy. The minor abdominal trauma that our patient sustained may have been the precipitating event for her first episode of angioedema. Women often note an association of HAE attacks with menstruation, and increased frequency of attacks has been noted with the use of oral contraceptives (5). Our patient had been started on the birth control pill before the onset of her illness and since stopping it has been free of attacks.

Acquired angioedema (AAE) has been associated with lymphoproliferative disorders and connective tissue diseases such as lupus (3). These cases can be distinguished from hereditary forms in that they usually present in older patients without a family history. Although these patients have normal C1-INH production, abnormal proteins in the serum trigger increased catabolism of C1-INH (type I AAE). Rare cases of autoantibody production against C1-INH have been described (type II AAE) (6). Angiotensin-converting enzyme (ACE) inhibitors are a well-recognized cause of angioedema. There are several case reports of ACE inhibitors causing isolated small bowel angioedema $(7,8)$. Bradykinin, a mediator of angioedema, is degraded by ACE; therefore, no patient with HAE should receive ACE inhibitors for fear of precipitating attacks of angioedema.

The management of acute attacks of angioedema focuses on supportive care with intravenous fluids for hypotension and narcotics for pain control $(2,4,9)$. Maintenance of the airway is of utmost importance. There is no evidence to support the use of adrenaline, histamine antagonists or corticosteroids during acute attacks (2). Purified C1-INH concentrate is available and can shorten the duration of an acute attack (10). Fresh, frozen plasma may be useful but carries a risk of transfusion reactions and infection transmission, and possibly fuels the complement cascade (9). Patients who have had airway edema or frequent abdominal attacks are candidates for maintenance therapy in the form of attenuated androgens using danazol or stanozolol. They increase C1-INH levels but are associated with masculinizing side effects and should not be used in prepubertal patients. Alternatively, antifibrinolytic agents such as epsilon-amino-

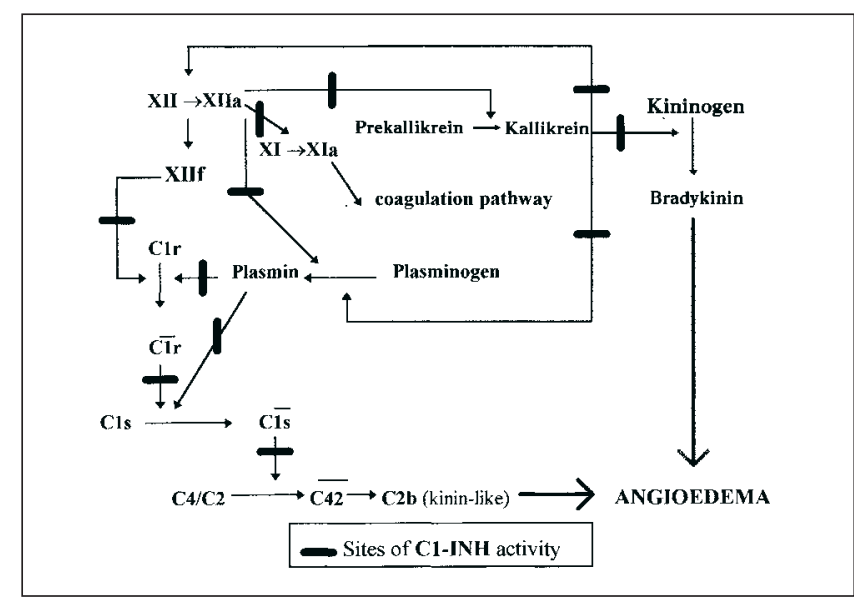

Figure 3) Pathophysiology of angioedema. C1 inhibitor (C1-INH) acts in the classical complement cascade and also the intrinsic coagulation pathway and kinin-forming system. Bradykinin and the kinin-like activity of $\mathrm{C} 2 b$ are important mediators of angioedema

caproic acid can prevent angioedema by inhibiting plasmin activity, although they have no effect on C1-INH levels. C1-INH infusions on a weekly basis can be used for maintenance therapy. Patients with HAE who require dental extractions or surgery should receive prophylaxis with androgens two weeks in advance or infusions of $\mathrm{C} 1$-INH or fresh frozen plasma the day of surgery. Treatment of the underlying neoplasm is most important in AAE type I, and immunosuppression or plasmapheresis can be used for AAE type II. Currently, our patient is being managed conservatively, although purified C1-INH has been made available to the patient's local hospital for use in future attacks.

\section{SUMMARY}

C1-INH is a rare disorder that often presents with abdominal complaints that can mimic other conditions. It is important to recognize small intestinal angioedema because it has a distinct pathogenesis and requires unique treatment.

\section{REFERENCES}

1. Osler W. Hereditary angioneurotic edema. Am J Med Sci 1888;93:362-7.

2. Huston DP, Bressler RB. Urticaria and angioedema. Med Clin North Am 1992;76:805-40.

3. Kulp-Shorten CL, Callen JP. Urticaria, angioedema and rheumatologic disease. Rheum Dis Clin North Am 1996;22:95-115.

4. Whaley K, Sim B, He S. Autoimmune C1-inhibitor deficiency. Clin Exp Immunol 1996;106:423-6.

5. Jacobs RL, Hoberman LJ, Goldstein HM. Angioedema of the small bowel caused by an angiotensin-converting enzyme inhibitor. Am J Gastroenterol 1994;89:127-8.

6. Abdelmalek MF, Douglas DD. Lisinopril-induced isolated visceral angioedema: review of ACE-inhibitor-induced small bowel angioedema. Dig Dis Sci 1997;42:847-50.

7. Orfan NA, Kolski GB. Angioedema and C1 inhibitor deficiency. Ann Allergy 1992;69:167-72.

8. Frank MM, Gelfand JA, Atkinson JP. Hereditary angioedema: the clinical syndrome and its management. Ann Intern Med 1976;84:580-93.

9. Moore GP, Hurley WT, Pace SA. Hereditary angioedema. Ann Emerg Med 1988;17:1082-6.

10. Gadek JE, Hosea SW, Gelfand JA, et al. Replacement therapy in hereditary angioedema. N Engl J Med 1980;302:542-6. 


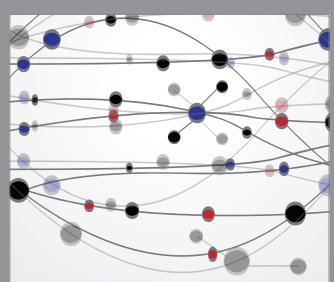

The Scientific World Journal
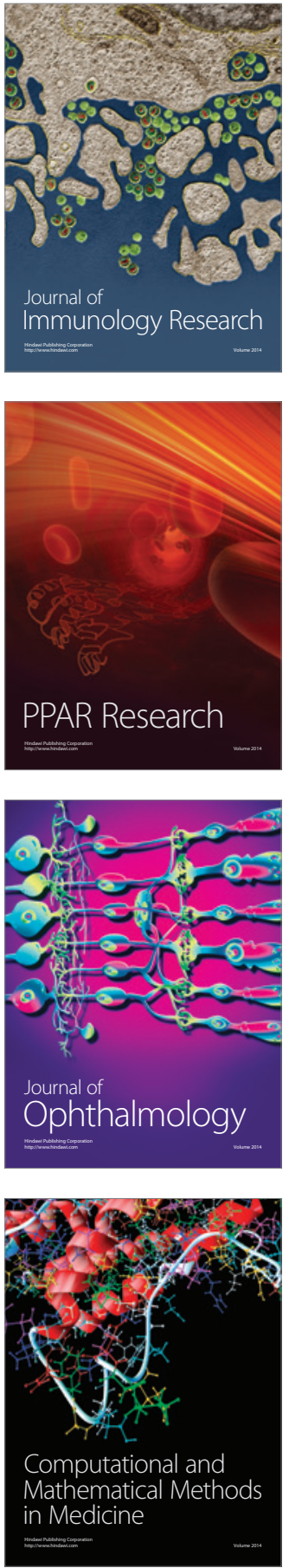

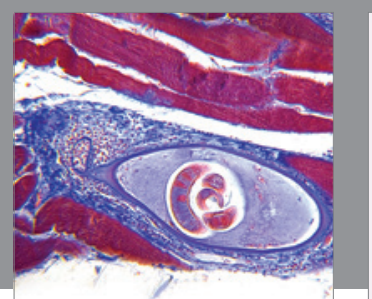

Gastroenterology Research and Practice

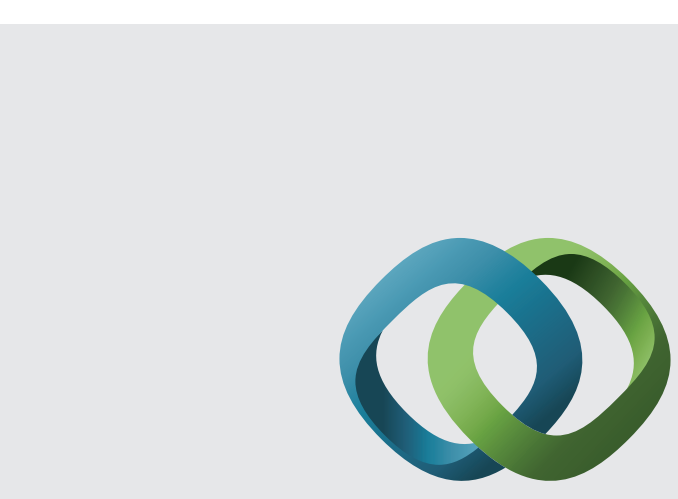

\section{Hindawi}

Submit your manuscripts at

http://www.hindawi.com
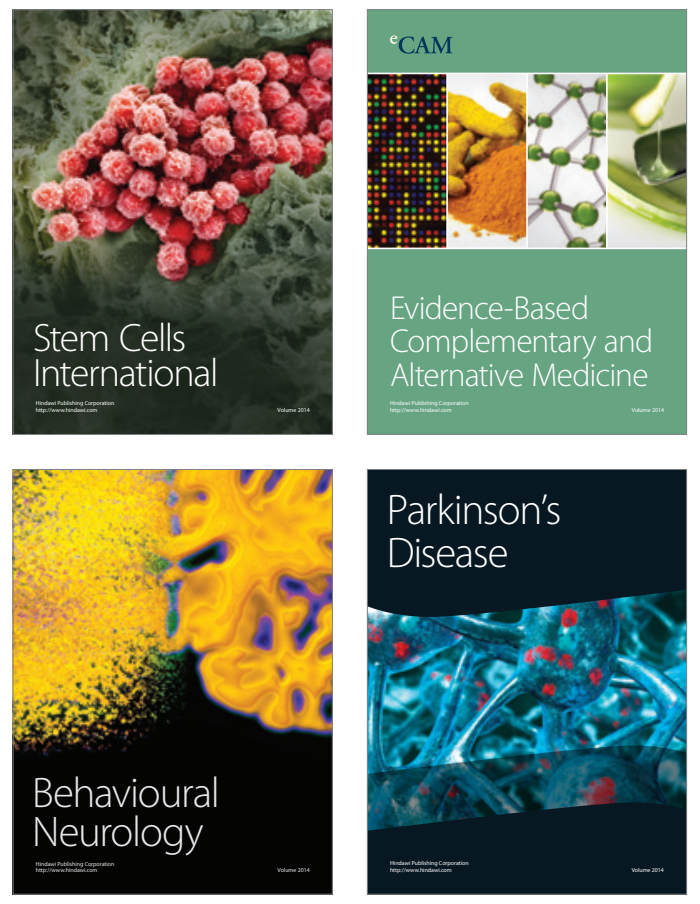
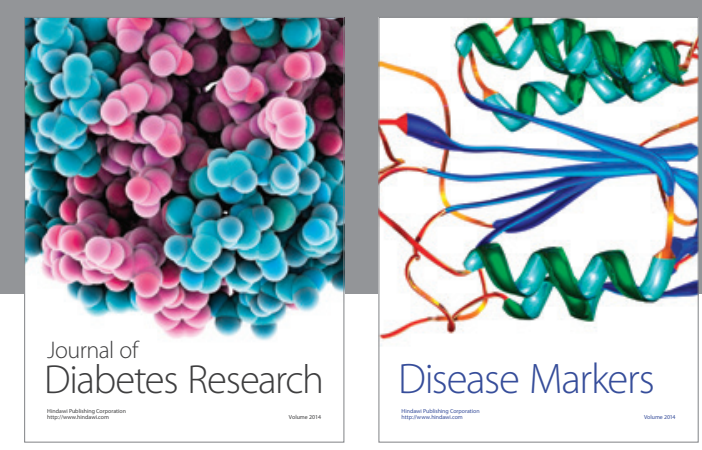

Disease Markers
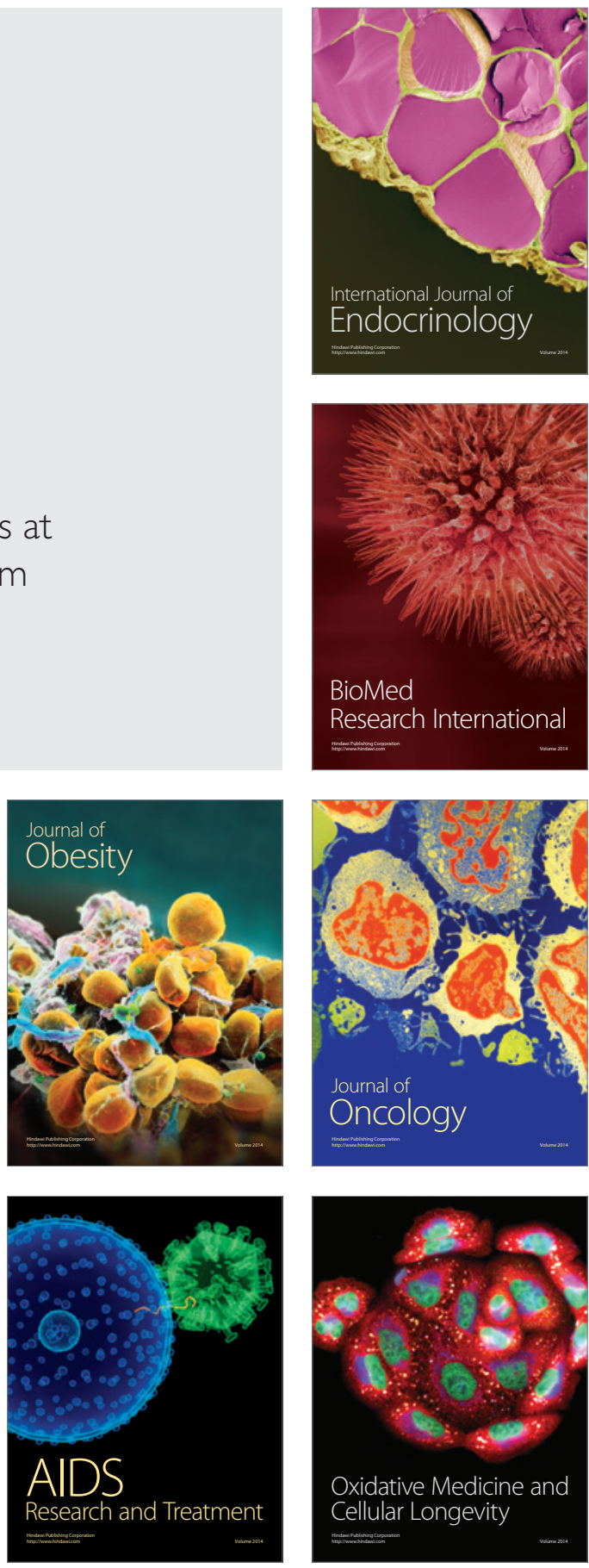